ORIGINAL ARTICLE

\title{
Genetic evolution of $\alpha$ fetoprotein producing gastric cancer
}

\author{
H Fujii, K Ichikawa, T Takagaki, Y Nakanishi, M Ikegami, S Hirose, T Shimoda
}

J Clin Pathol 2003;56:942-949

See end of article for authors' affiliations .....................

Correspondence to: Dr H Fujii, Department of Pathology II, Juntendo University School of Medicine, 2-1-1, Hongo, Bunkyo-ku, Tokyo 113 8421, Japan, hfujii@ med.juntendo.ac.jp

Accepted for publication 25 May 2003

\begin{abstract}
Background: $\alpha$ Fetoprotein (AFP) producing gastric cancer is an unusual form of aggressive adenocarcinoma with a complex histological picture, including enteroblastic and hepatoid differentiation. Aims: To investigate the genetic events underlying the phenotypic diversity in AFP producing gastric cancer and the ability of these tumours to produce AFP ectopically.

Methods: Multiple foci from 19 AFP producing gastric adenocarcinomas were microdissected and loss of heterozygosity $(\mathrm{LOH})$ analysis was performed with a panel of microsatellite markers on nine chromosomal arms.

Results: For informative cases, $\mathrm{LOH}$ was most frequently detected on $17 \mathrm{p}(100 \%)$, followed by $13 q(88 \%)$, $3 p(87 \%), 5 q$ and $9 p(80 \%), 11 q(70 \%), 18 q(58 \%), 16 q(53 \%)$, and $8 p(50 \%)$. The average fractional allelic loss was 0.72 . $\mathrm{LOH}$ was detected either homogeneously throughout the microdissected foci, or only in some parts of the neoplastic foci for each case. Heterogeneous patterns of $\mathrm{LOH}$ indicated genetic progression and/or divergence in clonal evolution. Furthermore, in six cases with heterogeneous $\mathrm{LOH}$ of $13 q, 13 q \mathrm{LOH}$ was restricted to immunohistochemically AFP positive neoplastic foci.

Conclusion: AFP-GC arises as an aggressive clone with extensive $\mathrm{LOH}$ and high fractional allelic loss. The presence of heterogeneous patterns of $\mathrm{LOH}$ suggested that the AFP producing carcinoma foci might evolve through genetic progression and/or genetic divergence. Silencing of the crucial gene on $13 q$ may be involved in the acquisition of the AFP producing phenotype.
\end{abstract}

A lpha fetoprotein (AFP) is a normal fetal serum glycoprotein, which is synthesised and secreted by fetal hepatocytes, yolk sac cells, and fetal gastrointestinal cells. ${ }^{12}$ Synthesis usually stops at birth, and hence its presence in the serum after 1 year of age is associated with pathological conditions. ${ }^{12}$ The presence of serum AFP has been well documented in some human cancers, including hepatocellular carcinoma (HCC) and yolk sac tumour. Serum AFP is raised in up to $80-90 \%$ of patients with HCC, and is a useful marker for the detection of HCC, in addition to monitoring tumour recurrence after surgery and adjuvant treatment. $^{2}$

AFP producing gastric cancer (AFP-GC) was first described by Bourreille in $1970 .^{3}$ Ishikura et al proposed the term "hepatoid adenocarcinoma of the stomach" for a gastric cancer with the histological features of hepatocytic differentiation and AFP production. ${ }^{4}$ Although rare, reported cases of AFP-GC have been accumulating, and this entity is now well recognised. ${ }^{5-12}$ Most AFP-GC cases show an aggressive clinical course, with frequent metastasis to the liver, lymph nodes, and other organs, and more than $90 \%$ of patients succumb within five years..$^{5} 101113$ Morphologically, in addition to the well documented hepatoid appearance of the tumour cells, these tumours often contain cells with clear cytoplasm and tubule formation, which are indicative of fetal enteroblastic differentiation. ${ }^{8}$ In fact, many of these tumours contain a combination of areas with ordinary tubular histology, tubulopapillary adenocarcinoma foci, poorly differentiated medullary carcinoma, and enteroblastic and hepatoid foci. ${ }^{45-9} 11$

\section{"Inactivation of tumour suppressor genes through deletion or mutation is thought to be crucial in the development of various human tumours"}

To our knowledge, no genetic studies have been conducted on AFP-GC. The genetic mechanism behind its unusually complex histology, capacity for heterotopic AFP production, and its aggressiveness still remains unknown. Inactivation of tumour suppressor genes through deletion or mutation is thought to be crucial in the development of various human tumours. Loss of heterozygosity $(\mathrm{LOH})$ is the deletion of the normal allele of a chromosomal region. $\mathrm{LOH}$ at a specific chromosomal locus in a tumour could indicate the presence of a tumour suppressor gene in the region of loss. Using microdissected tumour samples and subsequent LOH analysis, we previously revealed that genetic progression and heterogeneity accompany the phenotypic or histological diversity of tumours such as gynaecological carcinosarcomas and combined hepatocellular-cholangiocarcinomas. ${ }^{14} 15$ Thus, these genetic approaches would be useful methods for the genetic analysis of AFP-GCs showing complex histology. In our present study, in an attempt to reveal the genetic basis of the clonal evolution of AFP-GC, we microdissected multiple foci from 19 such cases and LOH patterns were analysed with a panel of microsatellite markers on nine chromosomal arms.

\section{MATERIALS AND METHODS}

\section{Tissue samples}

Nineteen cases of AFP-GC were identified in the archival pathology files of the pathology division, National Cancer Centre Research Institute and Hospital, Tokyo, Japan, and the department of pathology at Jikei University, School of Medicine, Tokyo, Japan. All the cases selected had been tested for the quality of DNA preservation for adequate and reproducible polymerase chain reaction (PCR) amplification. The samples came from 16 men and three women, whose ages ranged from 40 to 80 years, with a mean age of 61. All

\footnotetext{
Abbreviations: AFP, $\alpha$ fetoprotein; AFP-GC, $\alpha$ fetoprotein producing gastric cancer; FAL, fractional allelic loss; LOH, loss of heterozygosity; $\mathrm{HCC}$, hepatocellular carcinoma; H\&E, haematoxylin and eosin; HI, heterogeneity index; PCR, polymerase chain reaction
} 
the patients showed raised serum AFP concentrations, ranging from 42 to $2177000 \mathrm{ng} / \mathrm{ml}$. All samples were formalin fixed, paraffin wax embedded tissue blocks from surgically resected tumours. The maximum diameter of the tumours ranged from $18 \mathrm{~mm}$ to $120 \mathrm{~mm}$. The depth of tumour invasion was to the submucosa in one patient, muscularis propria in three, subserosa in five, and exposure to the serosal surface in 10. Lymph node metastases were detected in 14 patients. Histology of all the cases showed a complex mixture of ordinary tubular, tubulopapillary adenocarcinoma, poorly differentiated adenocarcinoma with medullary growth pattern, enteroblastic foci with tubular formation and clear cytoplasm, and areas of hepatoid differentiation with large polygonal cells with eosinophilic cytoplasm in solid or trabecular patterns. Periodic acid Schiff positive hyaline globules were frequently seen. In 11 cases, in addition to invasive foci, preinvasive intramucosal neoplastic foci were identified. Table 1 summarises the clinicopathological profiles.

\section{AFP immunohistochemistry}

Paraffin wax block sections of $3 \mu \mathrm{m}$ were immunohistochemically stained for AFP using anti-AFP monoclonal antibody (A0008; 1/5000 dilution; Dakopatts, Glostrup, Denmark). Except for cases HP24 and HP36 (AFP negative by stains but showed serum AFP of $300 \mathrm{ng} / \mathrm{ml}$ and $125 \mathrm{ng} /$ $\mathrm{ml}$, respectively), the AFP stains were positive for at least some of the neoplastic foci. The percentage of AFP positive foci ranged from less than 1\% (case HP27) to 70\% (cases HP6 and HP15) of the tumour area. Table 1 summarises the staining results.

\section{Tissue microdissection and DNA extraction}

Multiple tumour foci with different histological patterns, in addition to AFP positive and negative foci, were individually selected for microdissection. Serial $8 \mu \mathrm{m}$ sections were cut, dewaxed, stained with haematoxylin and eosin (H\&E), visualised with an inverted microscope, and microdissected using a 27 gauge needle. At least $90 \%$ of the microdissected cells were visually estimated to be tumour cells. For each case, four to 10 foci were microdissected. Stromal and inflammatory cells were collected separately and used as a normal control. The microdissected tissue was digested overnight at $50^{\circ} \mathrm{C}$ in buffer containing $0.5 \%$ NP40, $50 \mathrm{mM}$ Tris/ $\mathrm{HCl}, \mathrm{pH} 8.0$, ImM EDTA, and $200 \mu \mathrm{g} / \mathrm{ml}$ proteinase $\mathrm{K}$. The lysate was heated at $95^{\circ} \mathrm{C}$ for 10 minutes, and stored at $-20^{\circ} \mathrm{C}$ until used directly in the PCR reaction.

\section{Detection of $\mathrm{LOH}$}

The PCR reactions contained $1 \mu \mathrm{l}$ of DNA lysate, $0.4 \mu \mathrm{M}$ $\left[\gamma^{32} \mathrm{p}\right]$ ATP radiolabelled microsatellite primers, $0.2 \mathrm{mM}$ dNTP, $10 \mathrm{mM}$ Tris/HCl, pH 8.3, $1.5 \mathrm{mM} \mathrm{MgCl}_{2}, 50 \mathrm{mM} \mathrm{KCl}$, and $0.4 \mathrm{U}$ Taq polymerase in a total reaction volume of $10 \mu \mathrm{l}$. Taq was added to the reactions, which were prewarmed to $94^{\circ} \mathrm{C}$ (hot start PCR), and the samples were amplified with 35 cycles of PCR amplification. On average, each PCR reaction contained 100-200 cells. The PCR products were separated on a $5 \%$ denaturing polyacrylamide/urea/formamide gel and visualised using a phosphoimager (Bas 2500 Bio Imaging System; Fuji Film, Tokyo, Japan). The presence of LOH was defined as more than a $75 \%$ reduction of the relative intensity in one of the two alleles compared with the normal control. When only a proportion of the microdissected foci showed $\mathrm{LOH}$, the PCR reactions were repeated at least three times in duplicate to confirm the LOH and to exclude spurious PCR reactions. Other informative microsatellite markers located on the same chromosomal arm also confirmed LOH. If necessary, the microdissection was repeated. Fractional allelic loss (FAL) was calculated for each case as the number of chromosomal arms with at least one of the microdissected foci showing $\mathrm{LOH}$ divided by the number of chromosomal arms with informative markers. Because homogeneous LOH throughout the microdissected tumour foci is presumed to have occurred early in the neoplastic evolution, and heterogeneous LOH later during clonal progression and divergence, we calculated the heterogeneity index (HI) of each chromosomal arm as follows: HI is expressed as the number of cases with heterogeneous patterns of allelic loss divided by the total number of cases with one or more microdissected focus showing $\mathrm{LOH}$.

\section{Microsatellite markers}

All of the PCR primers for the microsatellite markers except for D13S171, D13S260, D13S168, and D13S154 were pur-

\begin{tabular}{|c|c|c|c|c|c|c|c|c|c|}
\hline Case & Sex & Age & $\begin{array}{l}\text { Serum AFP } \\
(\mathrm{ng} / \mathrm{ml})\end{array}$ & $\begin{array}{l}\text { Maximum } \\
\text { diameter }(\mathrm{mm})\end{array}$ & $\begin{array}{l}\text { Mucosal } \\
\text { lesion }\end{array}$ & Depth & $\begin{array}{l}\text { Presence of Ent } \\
\text { and/or Hep foci }\end{array}$ & $\begin{array}{l}\text { AFP } \\
\text { immunostain }\end{array}$ & $\begin{array}{l}\mathrm{LN} \\
\text { metastasis }\end{array}$ \\
\hline HP1 & M & 54 & 125 & 70 & + & ss & Ent & $40-50 \%$ & + \\
\hline HP2 & $\mathrm{F}$ & 51 & 3342 & 37 & + & $\mathrm{mp}$ & Ent & $20-30 \%$ & + \\
\hline HP4 & $\mathrm{F}$ & 60 & 42 & 70 & - & se & Ent & $<5 \%$ & + \\
\hline HP5 & M & 55 & 1092 & 60 & - & ss & Ent/Hep & $50 \%$ & - \\
\hline HP6 & M & 66 & 25400 & 42 & - & ss & $\mathrm{Ent} / \mathrm{Hep}$ & $60-70 \%$ & - \\
\hline HP7 & M & 42 & 15551 & 25 & + & ss & $\mathrm{Ent} / \mathrm{Hep}$ & $50-60 \%$ & - \\
\hline HP8 & M & 74 & 130 & 40 & + & $\mathrm{sm}$ & Ent & $50 \%$ & - \\
\hline HPQ & M & 53 & 179500 & 75 & - & se & $\mathrm{Ent} / \mathrm{Hep}$ & $<5 \%$ & + \\
\hline HP12 & $M$ & 53 & 39880 & 90 & + & se & $\mathrm{Ent} / \mathrm{Hep}$ & $5-10 \%$ & + \\
\hline HP14 & $M$ & 51 & 4103 & 74 & + & se & Ent/Hep & $10 \%$ & + \\
\hline HP15 & $M$ & 40 & $2.177 \times 10^{6}$ & 40 & + & se & $\mathrm{Ent} / \mathrm{Hep}$ & $\begin{array}{l}70 \% \text {, faint/ } \\
\text { negative in } \\
\text { the mucosa }\end{array}$ & + \\
\hline HP23 & $M$ & 66 & 1040 & 95 & - & se & Ent & $<10 \%$ & + \\
\hline HP24 & $M$ & 65 & 300 & 85 & + & ss & Нер & Negative & + \\
\hline HP26 & $M$ & 77 & 5300 & 100 & + & se & Ent/Hep & $<5 \%$ & + \\
\hline HP27 & $\mathrm{F}$ & 80 & 1100 & 90 & + & se & Нер & $<1 \%$ & + \\
\hline HP36 & $M$ & 67 & 125 & 60 & - & $\mathrm{mp}$ & Hep & Negative & - \\
\hline HP38 & $M$ & 54 & 2100 & 120 & - & se & Ent/Hep & $<3 \%$ & + \\
\hline HP4O & $M$ & 75 & 537 & 75 & Equivocal & se & $\mathrm{Ent} / \mathrm{Hep}$ & $<10 \%$ & + \\
\hline HP41 & M & 72 & 511 & 18 & + & $\mathrm{mp}$ & Hep & $<5 \%$ & + \\
\hline
\end{tabular}

AFP, $\alpha$ fetoprotein; Ent, focal enteroblastic foci are present; Ent/Hep, both enteroblastic and hepatoid foci are present; Hep, focal hepatoid foci are present; LN, lymph node; mp, muscularis propria; se, exposure to the serosal surface; sm, submucosa; ss, subserosa. 
chased from Research Genetics (Huntsville, Alabama, USA). The microsatellite markers were selected to cover chromosomal regions commonly deleted in gastric cancer, hepatocellular carcinoma, and many other types of epithelial cancer. The following primers were used: 3p (D3S1234, D3S1286, and D3S1293), 5q (D5S1956, D5S2072, D5S647, D5S644, and D5S346), 8p (D8S264, D8S261, D8S258, and D8S133), 9p (D9S1749, D9S1748, and D9S1752), 11q (Int2 and D11S29), 13q (D13S263 and D13S166), 16q (D16S265 and D16S261), 17p (TP53, Dl7S786, and CHRNB1), and 18q (D18S474, D18S487, D18S46, and D18S55).

Primers for the following markers on $13 \mathrm{q}$ were custom made with the following sequences: D13S260 (13q12-13), forward, 5' -tgtctccgttccatgaaaaa-3', reverse, 5'-cccagatataag gacctggcta-3'; D13S171 (13q12.3-13), forward, 5'-tagcaaca caagaaaaggatgc- $3^{\prime}$, reverse $5^{\prime}$-tctccccttccatcctcctc- $3^{\prime} ;$ D D 135168 (13q14.3), forward, 5'-catgatgctggactggacat-3', reverse, 5'tgcttgcttgtgcctatgtt-3'; D13S154 (13q31-32), forward, 5' agcctgcctgtctccatatc- $3^{\prime}$, reverse, $5^{\prime}$-gccctggtcttgactggtt- $3^{\prime}$.

\section{RESULTS}

\section{Loss of heterozygosity}

Overall, of nine chromosomal arms, an average of 4.6 chromosomal arms were deleted for each case. For informative cases, LOH was most frequently detected on $17 \mathrm{p}(100 \%)$, followed by $13 q(88 \%), 3 p(87 \%), 5 q$ and $9 p(80 \%), 11 q$ $(70 \%), 18 \mathrm{q}(58 \%), 16 \mathrm{q}(53 \%)$, and $8 \mathrm{p}(50 \%)$. LOH was detected either homogeneously throughout the microdissected foci or only in some of the foci, as described below. Except for two cases (HP24 and HP26), one to six chromosomal alleles were homogeneously deleted in all of the foci microdissected for each case, indicating a clonal neoplastic process. FAL ranged from 0.25 to 1.00 , with an average of 0.72 . Table 2 summarises the results of the genetic analysis.

\section{Heterogeneity index}

Figure 1 shows the cumulated frequencies of homogeneous/ heterogeneous LOH and HI. The lowest HI was seen for $18 \mathrm{q}$ (0.14), followed by $3 p(0.15)$ and $17 p(0.17)$. Therefore, these chromosomal deletions must occur early in the development of neoplasia. The highest HI was seen for $13 q(0.60)$, followed by $9 p$ and $16 q(0.38)$. These genetic alterations tend to occur later during clonal genetic progression and/or divergence.

\section{Clonal evolution of AFP-GC}

When patterns of homogeneous and heterogeneous LOH within the tumour are reconstituted, the relation between clonal evolution and tumour histology/AFP production was evident. Figures 2 and 3 show the neoplastic clone derived from the mucosal lesion with early LOH of $3 p, 5 q, 9 p, 17 p$, and $18 \mathrm{q}$ in case HPl. Histologically, these mucosal and invasive foci showed ordinal papillary and moderately differentiated tubular adenocarcinoma without AFP immunoreactivity ( $\mathrm{Tl}$ and $\mathrm{T} 4$ ). The tumour clone progressed with $\mathrm{LOH}$ of $13 \mathrm{q}$ in microdissected $\mathrm{T} 2$ and $\mathrm{T} 3$ foci, showing enteroblastic histology and acquiring AFP producing ability. In case HP15 (fig 4), homogeneous and extensive LOH of $3 p, 5 q, 8 p, 9 p$, and $11 q$ was detected throughout the microdissected mucosal and invasive foci. Additional LOH of $13 q$ was detected in the invasive foci with enteroblastic, poorly differentiated, solid and hepatoid foci, but not in the

Table 2 Summary of genetic analysis

\begin{tabular}{|c|c|c|c|c|}
\hline Case & Homogeneous LOH & Heterogeneous LOH & Genetic pattern & FAL \\
\hline HPI & $\begin{array}{l}\text { 3p (D3S1293), 5q (D5S644), 9p (D9S1748, D9S1752), } \\
17 p(C H R N B 1), 18 q(D 18 S 474, \text { D18S487, D18S55) }\end{array}$ & 13q (D13S171, D13S154) & Progression & 0.75 \\
\hline HP2 & 3p (D3S1293), 5q (D5S644), 9p (D9S1748, D9S1752) & $13 q(\alpha, \beta)(D 13 S 171, D 13 S 263, D 13 S 154)$ & Divergence & 0.57 \\
\hline HP4 & $\begin{array}{l}3 p \text { (D3S1234), } 11 q(\operatorname{lnt2}), 13 q \text { (D13S171), 18q (D18S474, } \\
\text { D18S55) }\end{array}$ & & Homogeneous & 0.67 \\
\hline HP5 & $\begin{array}{l}\text { 13q (D13S260, D13S263, D13S168, D13S166, D13S154), } \\
16 q(\mathrm{D} 16 \mathrm{~S} 261)\end{array}$ & & Homogeneous & 0.40 \\
\hline HP6 & $\begin{array}{l}\text { 3p (D3S1234, D3S1293), 5q (D5S647, D5S644), 8p } \\
\text { (D8S261, D8S133), 13q (D13S260, D13S171, D13S168, } \\
\text { D13S166), 16q (D16S261), 17p (TP53, D17S786) }\end{array}$ & & Homogeneous & 0.67 \\
\hline HP7 & $3 p(D 3 S 1234, D 3 S 1293), 16 q(D 16 S 265$, D16S261) & 9p (D9S1748, D9S1752), 17p (TP53, CHRNB1) & Progression & 0.50 \\
\hline HP8 & $13 q$ (D13S154), 17p (TP53, D17S786, CHRNB1) & $8 p$ (D8S133) & Progression & 1.00 \\
\hline HPQ & $\begin{array}{l}5 q \text { (D5S647, D5S644), 8p (D8S261, D8S133), 17p (TP53, } \\
\text { CHRNB1), 18q (D18S474, D18S55) }\end{array}$ & $\begin{array}{l}\text { 9p (D9S1748), 11q (Int 2), 13q (D13S260, D13S171, } \\
\text { D13168, D13S166) }\end{array}$ & Divergence & 1.00 \\
\hline HP12 & $\begin{array}{l}\text { 3p (D3S1293), 5q (D5S644), } 11 q \text { (D1 1S29), 16q (D16S265, } \\
\text { D16S261), 17p (TP53, CHRNB1), 18q (D18S474) }\end{array}$ & $13 q(D 13 S 168, D 13 S 260)$ & Progression & 0.88 \\
\hline $\mathrm{HP} 14$ & 3p (D3S1234, D3S1293), 17p (D17S786, CHRNB1) & $5 q$ (D5S644), 9p (D9S1748), 16q (D16S265) & Divergence & 0.65 \\
\hline HP15 & $\begin{array}{l}3 p \text { (D3S1293), 5q (D5S647, D5S644), 8p (D8S133), 9p } \\
\text { (D9S1748, D9S1752), 11 }(\text { (nnt 2) }\end{array}$ & $13 q$ (D13S171, D13S166, D13S154) & Progression & 0.86 \\
\hline HP23 & $\begin{array}{l}\text { 9p (D9S1748, D9S1752), 11q (Int2), 16q (D16S265), 17p, } \\
\text { (CHRNB1, TP53), 18q (D18S487) }\end{array}$ & 13q (D13S171, D13S154) & Progression & 0.86 \\
\hline HP24 & & $\begin{array}{l}\text { 3p (D3S1234), 5q (D5S647, D5S644), 8p (D8S133), } \\
\text { 13q (D13S171, D13S166), 16q (D16S265) }\end{array}$ & Complex & 1.00 \\
\hline HP26 & $\begin{array}{l}\text { 3p (D3S1234), 5q (D5S647), 13q (D13S171, D13S166), } \\
16 q \text { (D16S265, D16S261) (only in invasive foci) }\end{array}$ & $\begin{array}{l}\text { 3p (D3S1234), 5q (D5S647), 13q (D13S171, } \\
\text { D13S166), 16q (D16S265, D16S261), 18q } \\
\text { (D18S474, D18S55) (mucosal foci) }\end{array}$ & $\begin{array}{l}\text { Complex (mucosa) } \\
\text { Homogeneous } \\
\text { (invasion) }\end{array}$ & 1.00 \\
\hline HP27 & $3 p(D 3 S 1234)$ & $17 p(\alpha, \beta)(D 17 S 786$, CHRNB1) & Divergence & 0.25 \\
\hline HP36 & $13 q$ (D13S171, D13S168, D13S166, D13S154), 17p (TP53) & & Homogeneous & 0.50 \\
\hline HP38 & $\begin{array}{l}5 q(D 5 S 644), 11 q \text { (D1 1S29, Int 2), 13q (D13S260, } \\
\text { D13S171, D13S168), 17p (TP53) }\end{array}$ & & Homogeneous & 0.67 \\
\hline HP40 & $\begin{array}{l}3 p \text { (D3S1293), 5q (D5S647), 8p (D8S261, D8S133), 17p } \\
\text { (CHRNB1) }\end{array}$ & $\begin{array}{l}11 q \text { (Int 2, D11S29), 13q (D13S171, D13S168, } \\
\text { D13S166, D13S154) }\end{array}$ & Divergence & 0.88 \\
\hline HP41 & $\begin{array}{l}\text { 3p (D3S1293), 5q (D5S647, D5S644), 9p (D9S1749, } \\
\text { D9S1748), 18q (D18S474, D18S487) }\end{array}$ & & Homogeneous & 0.57 \\
\hline
\end{tabular}

Microsatellite markers listed showed LOH for each case.

$\alpha, \beta$, allelic losses of the opposite chromosomal arms; complex, single clonal process cannot be confirmed because of the complexity of the LOH pattern; divergence, single clonal process with subsequent genetic divergence; homogeneous, all the foci show the same genetic alteration; progression, linear genetic progression of a clone.

$\mathrm{FAL}$, fractional allelic loss; $\mathrm{LOH}$, loss of heterozygosity. 

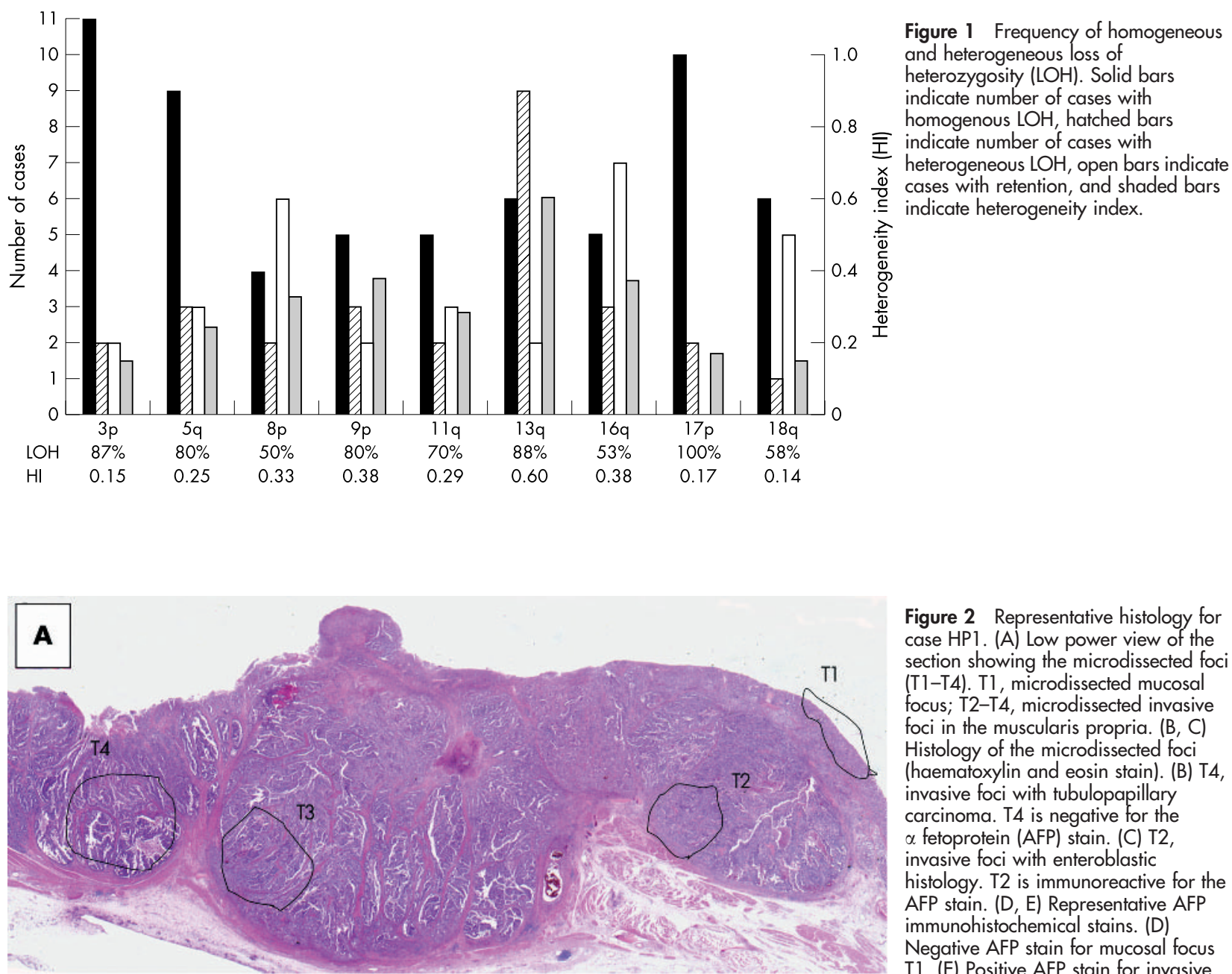

Figure 2 Representative histology for case HP1. (A) Low power view of the section showing the microdissected foci (T1-T4). T1, microdissected mucosal focus; T2-T4, microdissected invasive foci in the muscularis propria. $(B, C)$ Histology of the microdissected foci (haematoxylin and eosin stain). (B) T4, invasive foci with tubulopapillary carcinoma. T4 is negative for the $\alpha$ fetoprotein (AFP) stain. (C) T2, invasive foci with enteroblastic histology. T2 is immunoreactive for the AFP stain. (D, E) Representative AFP immunohistochemical stains. (D) Negative AFP stain for mucosal focus T1. (E) Positive AFP stain for invasive
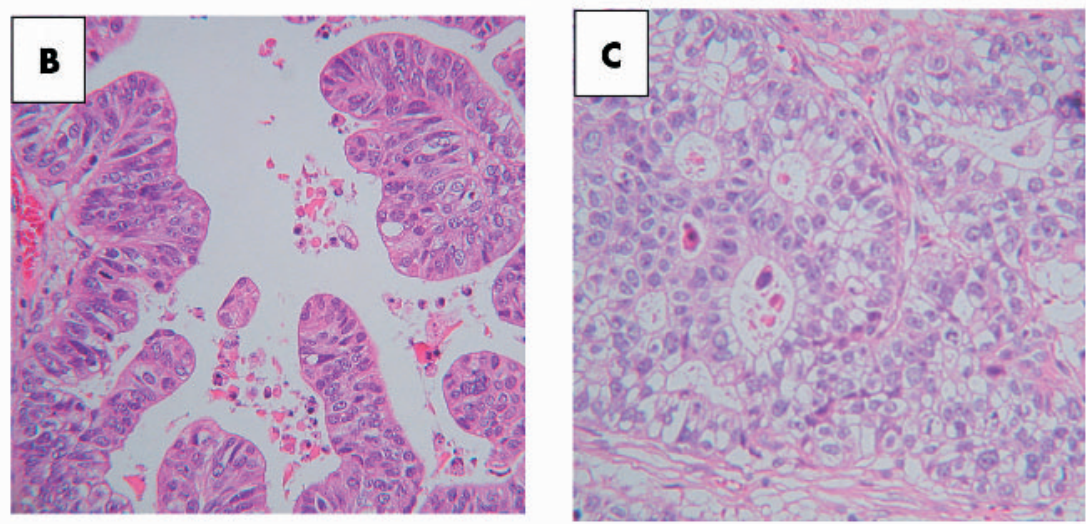
enteroblastic focus $\mathrm{T} 2$.
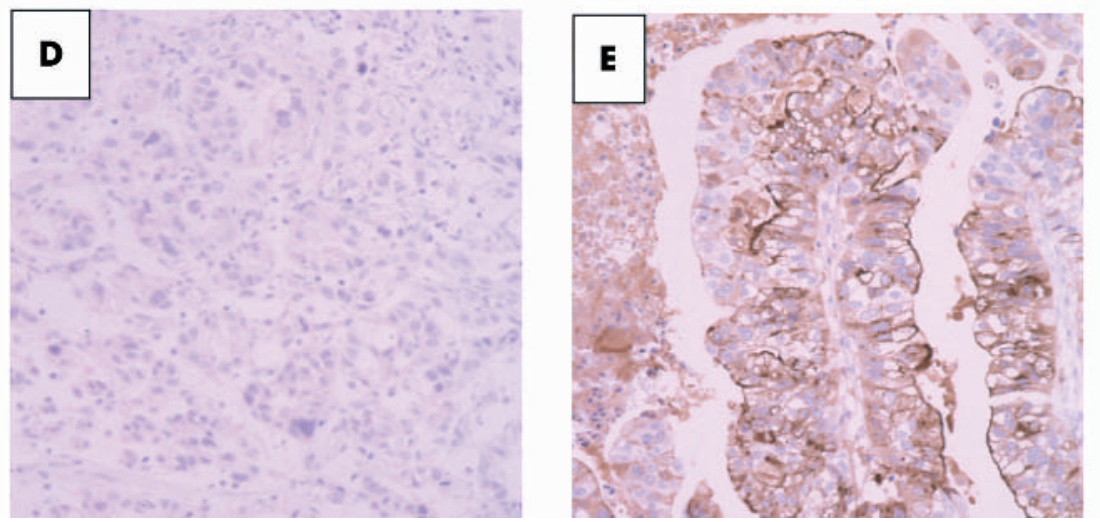

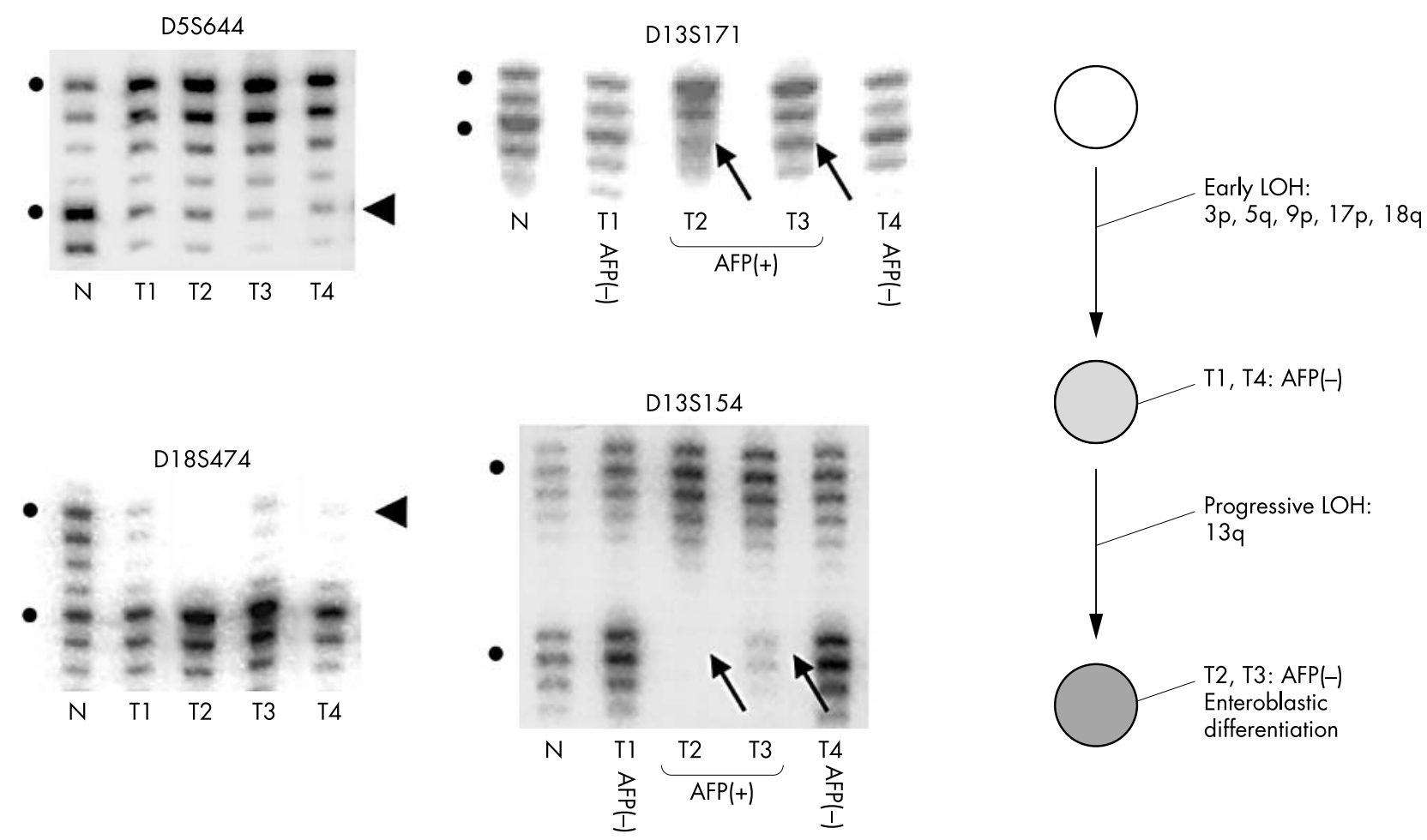

Figure 3 Representative gels and proposed genetic pathway for case HP1. Gels for D18S474 and D5S644 show homogeneous loss of heterozygosity $(\mathrm{LOH})$ for all of the foci microdissected. Arrowheads in the gels indicate LOH at all microdissected foci (T1-T4). Gels for D13S171 and D13S154 show $13 q \mathrm{LOH}$ only in invasive enteroblastic and $\alpha$ fetoprotein (AFP) positive foci, T2 and T3, but retention of mucosal (T1) and invasive tubulopapillary carcinoma foci (T4). Arrows indicate LOH of lower alleles for T2 and T3. Dot, normal alleles; N, normal control DNA; T, microdissected foci. The diagram summarises early LOH of 3p, 5q,9p, 17p, and 18q, followed by the progressive LOH of $13 q$ in $\alpha$ fetoprotein positive enteroblastic foci.

mucosal foci that were microdissected. AFP was strongly positive in the invasive foci, but unstained to faintly stained in the mucosal foci. Thus, enteroblastic and hepatoid foci genetically progressed from the early mucosal tumour, acquiring an AFP producing phenotype. However, the possibility of additional undetected genetic alterations between enteroblastic and hepatoid foci cannot be excluded. In case HP40 (figs 5 and 6), the lesion started with early LOH of 3p, 5q, 8p, and $17 p$, which was detected in the moderately/poorly differentiated adenocarcinoma foci (T1) and enteroblastic foci (T2). Further genetic progression and divergence was detected in hepatoid foci (AFP positive) with $13 \mathrm{q}$ LOH (T3) or $1 \mathrm{lq}$ LOH (T4). Furthermore, in six cases (cases HP1, HP2, HP9, HP12,
D9S 1752

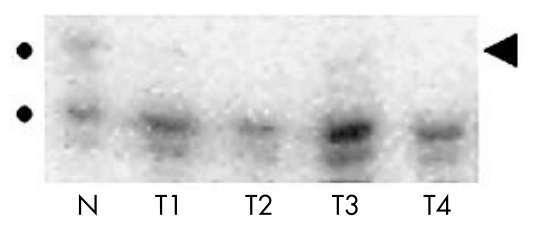

$\mathrm{LOH}: 3 p, 5 q, 8 p, 9 p, 11 q$

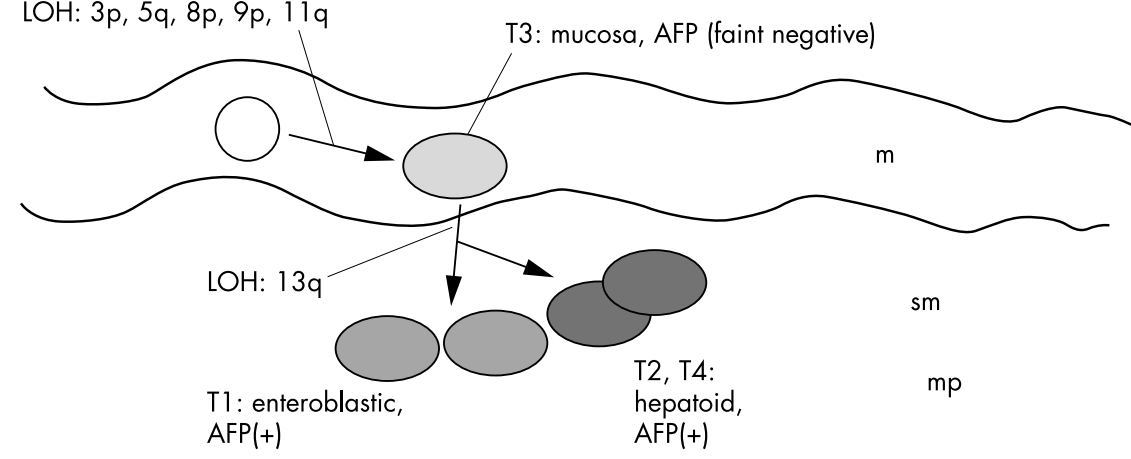

Figure 4 Representative gels and proposed genetic pathway for case HP15. Arrowhead in the gel for D9S1752 indicates homogeneous loss of heterozygosity (LOH) of all T1-T4 foci. Arrows in the gel for D13S171 indicate $\mathrm{LOH}$ of $\mathrm{T} 1, \mathrm{~T} 2$, and $\mathrm{T} 4$, but not T3. Dot, normal alleles; $N$, normal control DNA; T1,T2, and T4,

microdissected submucosal invasive foci with enteroblastic and hepatoid features; T3, intramucosal tumour focus microdissected. $\alpha$ Fetoprotein (AFP) is strongly positive in invasive foci but faint/negative in the mucosal T3 focus. The diagram shows early and homogeneous $\mathrm{LOH}$ of $3 p, 5 q, 8 p, 9 p$, and $11 q$, including the mucosal focus. Subsequent $\mathrm{LOH}$ of $13 q$ is identified in invasive enteroblastic and hepatoid foci (T1, T2, and T4). 

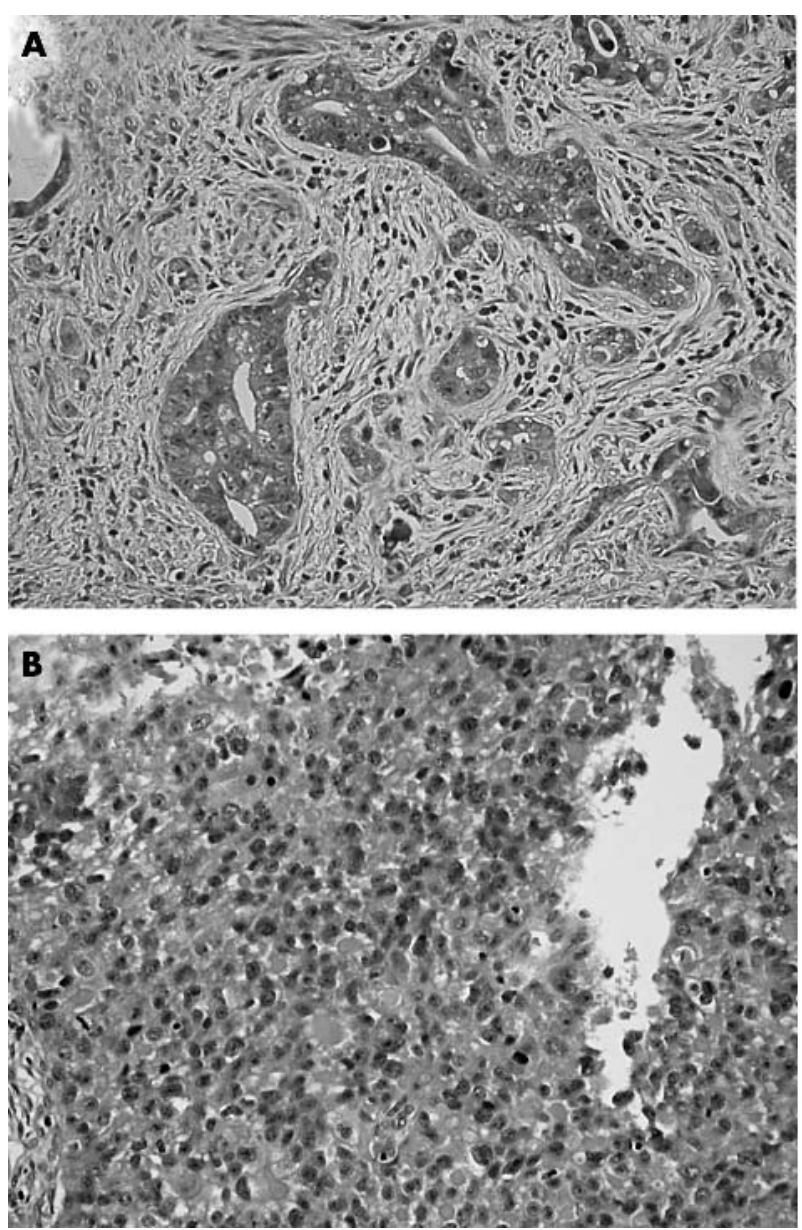

Figure 5 Representative histology for case HP40. (A) Ordinary adenocarcinoma focus in the submucosa, T1 (haematoxylin and eosin (H\&E) stain). T1 and T2 foci are negative for $\alpha$ fetoprotein (AFP) immunostaining. (B) Hepatoid carcinoma foci in the muscularis propria, T3 (H\&E stain). Hepatoid foci, T3 and T4, are positive for AFP immunostaining.

HP15, and HP40) with heterogeneous patterns of $13 \mathrm{q} \mathrm{LOH,}$ 13q LOH was preferentially detected in AFP immunoreactive foci with solid, poorly differentiated adenocarcinoma foci and enteroblastic and/or hepatoid differentiation.

\section{DISCUSSION}

AFP is a glycoprotein that is produced by the fetal liver and fetal intestine. ${ }^{2}$ Embryologically, the liver arises as a ventral outgrowth of the distal end of the fetal foregut. Because of the embryological proximity, it has been speculated that the emergence of AFP producing hepatoid foci, or enteroblastic foci in gastric cancer, results from the dedifferentiation of the tumour cells to these progenitor cell types. ${ }^{12}$ Our present genetic study has revealed the genetic process of so called dedifferentiation of gastric carcinoma cells in the evolution of AFP-GC for the first time. Extensive LOH with high FAL (average of 0.72) seen in AFP-GC, as compared with the reported FAL of $0.288-0.472$ in gastric cancer, ${ }^{16}$ may reflect the very aggressive biological behaviour and grave prognosis known for these tumours. Because extensive LOH was detected homogenously throughout the microdissected foci in many cases, AFP-GC may initially arise as a very aggressive clone with high FAL, and may clonally expand very rapidly. Thus, phenotypic diversity seems to be conferred by extensive genetic alterations of these neoplastic clones. Alternatively, AFP-GC may evolve through genetic progression and/or divergence with the acquisition of the AFP producing phenotype. We saw cases in which ordinary tubular or tubulopapillary carcinoma foci genetically progressed or diverged in some of the invasive foci. Only these progressed foci acquired the capacity to produce AFP. These foci showed various histological features, including poorly differentiated medullary carcinoma, enteroblastic carcinoma, and hepatoid carcinoma. In fact, in most of the cases with recognisable mucosal lesions, genetic progression, and/or divergence occur in the invasive foci, indicating that the AFP-GC phenotype is acquired in the invasive foci. Previous studies have described the presence of hepatoid foci in deep invasive foci, which can be clearly explained by our clonal genetic patterns. There are case reports of only metastatic gastric cancer foci showing a hepatoid pattern and AFP production. ${ }^{7}{ }^{17}$ These cases may also be examples of clonal genetic progression and divergence in the metastatic foci with the acquisition of the AFP producing phenotype.

"It is interesting that the loci of $13 q$ that are commonly deleted in $\alpha$ fetoprotein (AFP) producing gastric carcinoma are also frequently deleted in hepatocellular carcinoma, which often presents with raised serum AFP values"

In ordinary gastric cancers, $\mathrm{LOH}$ has been frequently detected on 1p, 1q, 2q, 3p, 4p, 5q, 6p, 7p, 8p, 9p, 11q, 13q, $14 \mathrm{q}, 17 \mathrm{p}, 18 \mathrm{q}$, and $21 \mathrm{q} \cdot{ }^{16}{ }^{18-21}$ In hepatocellular carcinomas, 1q, 2q, 4q, 6q, 8p, 8q, 9p, 9q, 10q, 13q, 14q, 16q, 17p, and 19p have been shown to be frequently deleted..$^{22-25}$ Thus, most of the regions of $\mathrm{LOH}$ detected in AFP-GC are also commonly deleted loci in both GC and HCC. However, there may be several crucial LOH regions that are particularly important for ectopic AFP production and the unique histological features of AFP-GC.

In our present study, 13q LOH was often associated with AFP immunoreactive tumour foci. One possibility is that a certain gene on 13q may function as a negative regulator of AFP production in normal cells. LOH of the gene locus and additional alteration of the remaining allele may silence or downregulate the gene. These possibilities remain to be investigated in future work. It is interesting that the loci of 13q that are commonly deleted in AFP-GC are also frequently deleted in HCC, which often presents with raised serum AFP values. $^{23} 2526$

Other than the stomach, rare cases of AFP producing or hepatoid carcinomas have been reported in the extrahepatic organs, including the lung, ${ }^{27}$ ovary, ${ }^{28}$ endometrium, ${ }^{29}$ colorectum, $^{30}$ gall bladder, ${ }^{31}$ urinary bladder, ${ }^{32}$ kidney, ${ }^{33}$ and pancreas. ${ }^{34}$ Most showed aggressive clinical behaviour, with metastasis at the time of diagnosis. Histologically, many of them show a complex combination of various histological patterns, including poorly differentiated adenocarcinoma, hepatoid foci, enteroblastic foci with clear cytoplasm, and

\section{Take home messages}

- $\alpha$ Fetoprotein producing gastric carcinoma (AFP-GC) arises as an aggressive clone with extensive loss of heterozygosity $(\mathrm{LOH})$ and high fractional allelic loss

- Because heterogeneous patterns of $\mathrm{LOH}$ are seen, the AFP producing carcinoma foci might evolve through genetic progression and/or genetic divergence

- Silencing of a crucial tumour suppressor gene on 13q may be involved in the acquisition of the AFP producing phenotype 

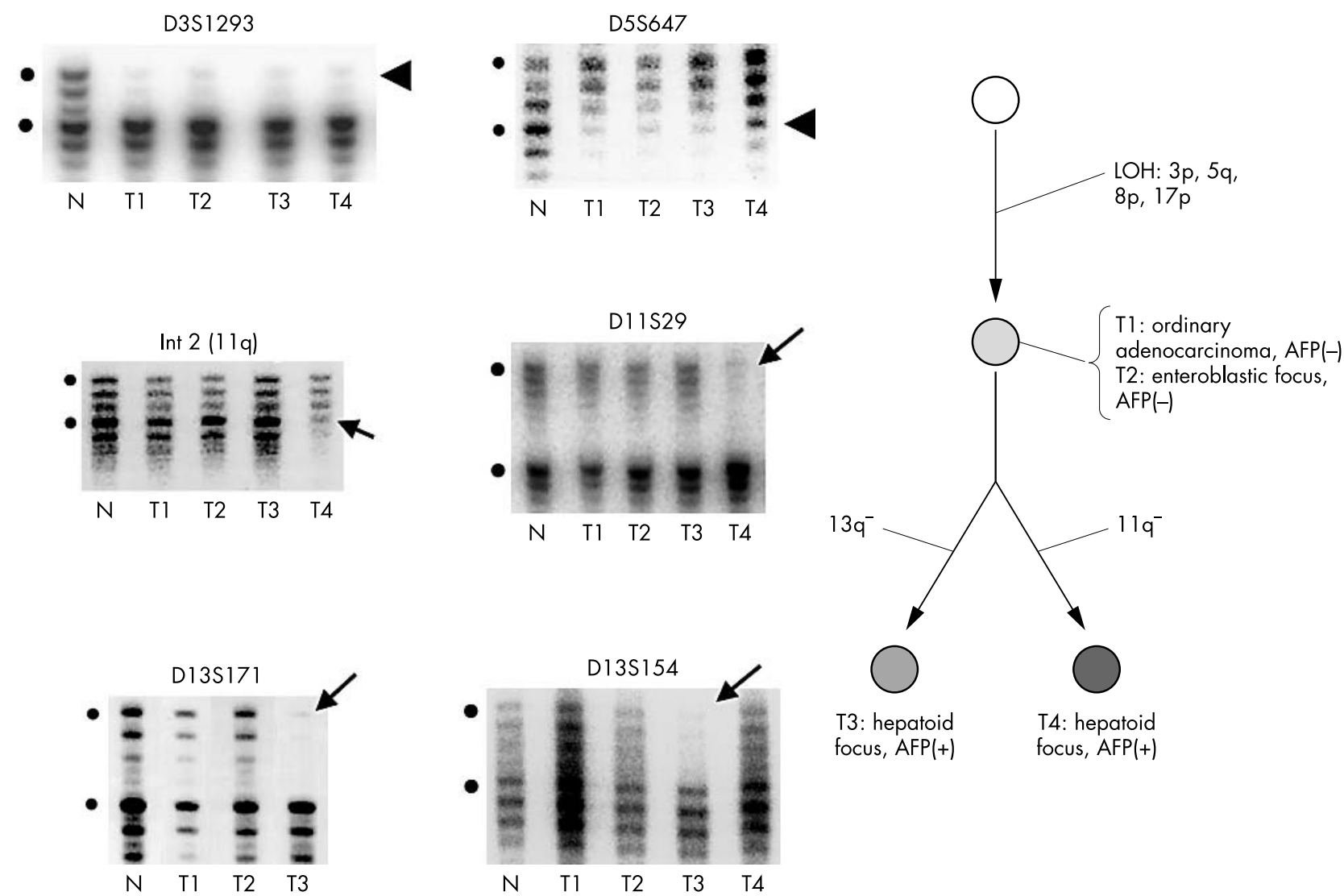

Figure 6 Gels and deduced genetic pathways for HP40. Arrowheads in gels for D3S1293 and D5S647 indicate loss of heterozygosity (LOH) of all foci T1-T4. Arrows in the gels for Int 2 (1 lq) and D1 1S29 indicate $11 \mathrm{q} \mathrm{LOH}$ of only T4. Arrows in the gels for D13S171 and D13S154 indicate 13q $\mathrm{LOH}$ of only T3. Dot, normal alleles; N, normal control DNA; T, microdissected foci. T1 is a microdissected submucosal focus, and T2-T4 are microdissected foci in the muscularis propria. The diagram summarises early and homogeneous $\mathrm{LOH}$ of $3 p, 5 q, 8 p, 17 p$, followed by divergent $\mathrm{LOH}$ of $13 q$ in $\alpha$ fetoprotein (AFP) positive hepatoid foci (T3), and $11 q \mathrm{LOH}$ in another hepatoid focus (T4).

yolk sac tumour-like foci. None of these cases has been genetically studied, but we speculate that similar and unique clonal genetic alterations may be involved in the abnormal differentiation and ectopic induction of the AFP gene in these tumours also.

In conclusion, AFP-GC arises as an aggressive clone with extensive LOH. Further genetic progression and divergence may confer subclones with the capacity to produce AFP and unique histological features.

\section{ACKNOWLEDGMENTS}

We thank Mr D Mrozek for reviewing the manuscript. Supported in part by a research grant from the Ministry of Education, Culture, Sports, Science and Technology of Japan.

\section{Authors' affiliations}

H Fujii, T Takagaki, S Hirose, Juntendo University School of Medicine, 2-1-1, Hongo, Bunkyo-ko, Tokyo, 113-8421, Japan

K Ichikawa, Department of Pathology, Dokkyo University School of Medicine, Tochigi, Japan

Y Nakanishi, T Shimoda, Pathology Division, National Cancer Centre Research Institute and Hospital, Tokyo, Japan

M Ikegami, Jikei University School of Medicine, Tokyo, Japan

\section{REFERENCES}

1 Gitlin D, Perricelli A, Gitlin GM. Synthesis of $\alpha$-fetoprotein by liver, yolk sac, and gastrointestinal tract of the human conceptus. Cancer Res 1972;32:979-82.

2 Alpert E. Human alpha 1-fetoprotein (AFP): developmental biology and clinical significance. Prog Liver Dis 1976;5:337-49.
3 Bourreille J, Metayer P, Sauger F, et al. Existence d'alpha foetoproteine au cours d'un cancer secondaire du foie d'origine gastrique. Presse Med 1970;78:1277-8.

4 Ishikura H, Fukasawa Y, Ogasawara K, et al. An AFP-producing gastric carcinoma with features of hepatic differentiation. A case report. Cancer 1985;56:840-8.

5 delorimier A, Park F, Aranha GV, et al. Hepatoid carcinoma of the stomach. Cancer 1993:71:293-6.

6 Giustozzi G, Goracci G, Bufalari A, et al. Hepatoid carcinoma of the stomach: is it still an unusual anatomo-clinical entity? Six case-reports. J Exp Clin Cancer Res 1999; 18:571-3.

7 Kodama T, Kameya T, Hirota T, et al. Production of alpha-fetoprotein, normal serum proteins, and human chorionic gonadotropin in stomach cancer: histologic and immunohistochemical analyses of 35 cases. Cancer 1981;48: 1647-55

8 Matsunou $\mathrm{H}$, Konishi $\mathrm{F}$, Jalal RE, et al. Alpha-fetoprotein-producing gastric carcinoma with enteroblastic differentiation. Cancer 1994;73:534-40.

9 Motoyama T, Aizawa K, Watanabe $\mathrm{H}$, et al. Alpha-fetoprotein producing gastric carcinomas: a comparative study of three different subtypes. Acta Pathol Jpn 1993;43:654-61.

10 Nagai E, Ueyama T, Yao T, et al. Hepatoid adenocarcinoma of the stomach. A clinicopathologic and immunohistochemical analysis. Cancer 1993:72:1827-35.

11 Ishikura H, Kirimoto K, Shamoto $M$, et al. Hepatoid adenocarcinomas of the stomach. An analysis of seven cases. Cancer 1986;58:119-26.

12 Ritter JH, Mills SE, Gaffey MJ, et al. Clear cell tumors of the alimentary tract and abdominal cavity. Semin Diagn Pathol 1997;14:213-19.

13 Chang YC, Nagasue N, Kohno H, et al. Clinicopathologic features and longterm results of alpha-fetoprotein-producing gastric cancer. Am J Gastroenterol 1990:85:1480-5.

14 Fujii $\mathrm{H}$, Zhu XG, Matsumoto T, et al. Genetic classification of combined hepatocellular-cholangiocarcinoma. Hum Pathol 2000;31:1011-17.

15 Fujii H, Yoshida M, Gong ZX, et al. Frequent genetic heterogeneity in the clonal evolution of gynecological carcinosarcoma and its influence on phenotypic diversity. Cancer Res 2000;60:1 14-20.

16 Choi SW, Park SW, Lee KY, et al. Fractional allelic loss in gastric carcinoma correlates with growth patterns. Oncogene 1998;17:2655-9. 
17 Kang GH, Kim YI. Alpha-fetoprotein-producing gastric carcinoma presenting focal hepatoid differentiation in metastatic lymph nodes. Virchows Arch 1998;432:85-7.

18 Cho JH, Noguchi M, Ochiai A, et al. Loss of heterozygosity of multiple tumor suppressor genes in human gastric cancers by polymerase chain reaction. Lab suppressor genes in hum
Invest 1996;74:835-41.

19 Nishizuka S, Tamura G, Terashima M, et al. Loss of heterozygosity during the development and progression of differentiated adenocarcinoma of the stomach. J Pathol 1998;185:38-43.

20 Tahara E. Molecular mechanism of stomach carcinogenesis. J Cancer Res Clin Oncol 1993; 1 19:265-72

21 Yustein AS, Harper JC, Petroni GR, et al. Allelotype of gastric adenocarcinoma. Cancer Res 1999;59:1437-41.

22 Nagai $H$, Pineau $P$, Tiollais $P$, et al. Comprehensive allelotyping of human hepatocellular carcinoma. Oncogene 1997; 14:2927-33.

23 Okabe H, Ikai I, Matsuo K, et al. Comprehensive allelotype study of hepatocellular carcinoma: potential differences in pathways to hepatocellular carcinoma between hepatitis B virus-positive and -negative tumors. Hepatology 2000;31:1073-9.

24 Piao Z, Park C, Park JH, et al. Allelotype analysis of hepatocellular carcinoma. Int J Cancer 1998;75:29-33.

25 Lin YW, Sheu JC, Liu LY, et al. Loss of heterozygosity at chromosome 13q in hepatocellular carcinoma: identification of three independent regions. Eur J Cancer 1999;35:1730-4.
26 Kuroki T, Fujiwara Y, Nakamori S, et al. Evidence for the presence of two tumour-suppressor genes for hepatocellular carcinoma on chromosome 13q Br J Cancer 1995;72:383-5.

27 Ishikura $H$, Kanda $M$, Ito $M$, et al. Hepatoid adenocarcinoma: a distinctive histological subtype of alpha-fetoprotein-producing lung carcinoma. Virchows Arch A Pathol Anat Histopathol 1990;417:73-80.

28 Ishikura H, Scully RE. Hepatoid carcinoma of the ovary. A newly described tumor. Cancer 1987;60:2775-84.

29 Hoshida Y, Nagakawa T, Mano S, et al. Hepatoid adenocarcinoma of the endometrium associated with alpha-fetoprotein production. Int J Gynecol Pathol 1996;15:266-9.

30 Hocking GR, Shembrey M, Hay D, et al. Alpha-fetoprotein-producing adenocarcinoma of the sigmoid colon with possible hepatoid differentiation. Pathology 1995;27:277-9.

31 Vardaman C, Albores-Saavedra J. Clear cell carcinomas of the gallbladder and extrahepatic bile ducts. Am J Surg Pathol 1995;19:91-9.

32 Sinard J, Macleay L, Jr, Melamed J. Hepatoid adenocarcinoma in the urinary bladder. Unusual localization of a newly recognized tumor type. Cancer 1994:73:1919-25.

33 Ishikura $H$, Ishiguro $T$, Enatsu $C$, et al. Hepatoid adenocarcinoma of the renal pelvis producing alpha-fetoprotein of hepatic type and bile pigment. Cancer 1991;67:3051-6.

34 Yano $\mathrm{T}$, Ishikura $\mathrm{H}, \mathrm{Wada} \mathrm{T}$, et al. Hepatoid adenocarcinoma of the pancreas. Histopathology 1999;35:90-2.

\section{Clinical Evidence - Call for contributors}

Clinical Evidence is a regularly updated evidence based journal available worldwide both as a paper version and on the internet. Clinical Evidence needs to recruit a number of new contributors. Contributors are health care professionals or epidemiologists with experience in evidence based medicine and the ability to write in a concise and structured way.

\section{Currently, we are interested in finding contributors with an interest in} the following clinical areas:

Altitude sickness; Autism; Basal cell carcinoma; Breast feeding; Carbon monoxide poisoning; Cervical cancer; Cystic fibrosis; Ectopic pregnancy; Grief/bereavement; Halitosis; Hodgkins disease; Infectious mononucleosis (glandular fever); Kidney stones; Malignant melanoma (metastatic); Mesothelioma; Myeloma; Ovarian cyst; Pancreatitis (acute); Pancreatitis (chronic); Polymyalgia rheumatica; Post-partum haemorrhage; Pulmonary embolism; Recurrent miscarriage; Repetitive strain injury; Scoliosis; Seasonal affective disorder; Squint; Systemic lupus erythematosus; Testicular cancer; Varicocele; Viral meningitis; Vitiligo However, we are always looking for others, so do not let this list discourage you.

Being a contributor involves:

- Appraising the results of literature searches (performed by our Information Specialists) to identify high quality evidence for inclusion in the journal.

- Writing to a highly structured template (about 2000-3000 words), using evidence from selected studies, within 6-8 weeks of receiving the literature search results.

- Working with Clinical Evidence Editors to ensure that the text meets rigorous epidemiological and style standards.

- Updating the text every eight months to incorporate new evidence.

- Expanding the topic to include new questions once every 12-18 months.

If you would like to become a contributor for Clinical Evidence or require more information about what this involves please send your contact details and a copy of your CV, clearly stating the clinical area you are interested in, to Claire Folkes (cfolkes@bmigroup.com).

\section{Call for peer reviewers}

Clinical Evidence also needs to recruit a number of new peer reviewers specifically with an interest in the clinical areas stated above, and also others related to general practice. Peer reviewers are health care professionals or epidemiologists with experience in evidence based medicine. As a peer reviewer you would be asked for your views on the clinical relevance, validity, and accessibility of specific topics within the journal, and their usefulness to the intended audience (international generalists and health care professionals, possibly with limited statistical knowledge). Topics are usually 2000-3000 words in length and we would ask you to review between 2-5 topics per year. The peer review process takes place throughout the year, and our furnaround time for each review is ideally 10-14 days.

If you are interested in becoming a peer reviewer for Clinical Evidence, please complete the peer review questionnaire at www.clinicalevidence.com or contact Claire Folkes(cfolkes@bmigroup.com). 